\title{
Increasing Risk and Self-Protection Activities
}

\author{
by Georges Dionne* and Louis Eeckhoudt*
}

\section{Introduction}

Since Rothschild and Stiglitz [1970] have defined the concept of a mean preserving spread in risk, it is known that contrary to common sense, increases in risk do not necessarily induce risk-averse individuals to engage into less risky activities. However, in some specific cases, a more plausible result can be obtained. One of these was already indentified by Rothschild and Stiglitz [1971] themselves in dealing with "bets" - i.e. a portfolio allocation decision with only two possible risky outcomes - : in this situation an increase in risk always leads a risk-averse decision maker to assume less risk. (See also Meyer and Ormiston [1985]). Recently, Karni [1983] extended the result to the case of state-dependent utility functions under the restriction of the so-called reference set.

In this paper, by considering the decision to self-protect against a potential loss of a given amount -i.e. in the situation of a bet - we show that even under state-independent utility functions, one cannot a priori sign the impact of a compensated change in risk upon the optimal level of care.

This result confirms and extends previous ones that have been presented in the literature. In their pathbreaking article on insurance and self-protection, Ehrlich and Becker [1972] have already noted that "the incentive to self-protect, unlike the incentive to insure, is not so dependent on attitudes toward risk" (pp. 639-640). More recently, Boyer-Dionne [1984] and Dionne-Eeckhoudt [1985] have shown that increases in risk aversion may lead to a reduction in the level of self-protection activities. Similarly in a model which combines output and self-protection decisions, Hiebert [1983] has stressed other ambiguities related to the optimal response of self-protection.

In this paper we consider how an exogenous mean-preserving change in risk affects the optimal level of care ${ }^{1}$.After presenting the model in Section 2, we discuss in Section 3 the impact of a compensated increase in risk. We then present in the following section a

\footnotetext{
* Université de Montréal and Facultés Catholiques de Mons et de Lille, respectively. This research was done partly while L. Eeckhoudt was visiting the Economics Department at the Université de Montréal and also while G. Dionne was visiting the Facultés Catholiques de Mons. We thank M. Pellerin for efficient computing assistance and CRSH (Canada) for financial support. Comments by an anonymous referee are also acknowledged.

${ }^{1}$ Hiebert [1983] has raised a similar question except that he has considered a non-mean-preserving change in risk.
} 
sufficient condition to obtain unambiguous comparative statics results. We also show with the help of an example that if it is not satisfied, a counter-intuitive outcome may occur. We summarize the main results in a short conclusion.

\section{The model}

Let us consider an individual who can affect the probability $(0<p<1)$ of loss $(l)$ by self-protection activities $(x)$ with a monetary cost $(c(x))$. We assume that the partial derivative of $p$ with respect to $x$ is negative $\left(p_{x}<0\right)$ while its second derivative $\left(p_{x x}\right)$ is non-negative. Marginal cost of $x\left(c_{x}\right)$ is positive and non-decreasing $\left(c_{x x} \geq 0\right)$.

This individual is risk averse (neutral) and his utility depends only upon final wealth $(W)$ with the usual properties $U^{\prime}(W)>0$ and $U^{\prime \prime}(W) \leq 0$. $W_{o}$ stands for initial wealth.

Given these specifications, his expected utility is equal to:

$$
E[U]=p(x) U\left(W_{o}-l-c(x)\right)+(1-p(x)) U\left(W_{o}-c(x)\right)
$$

From now on, $W_{o}-l-c(x) \equiv A$ and $W_{o}-c(x) \equiv B$ with $A<B$.

The optimal $x\left(x^{*}\right)$ is found by solving:

$$
p_{x}\left(x^{*}\right)[U(A)-U(B)]-c_{x}\left(x^{*}\right)\left[p\left(x^{*}\right) U^{\prime}(A)+\left(1-p\left(x^{*}\right)\right) U^{\prime}(B)\right]=0 .
$$

We assume that the specification of the problem is such that the second-order condition is automatically satisfied ${ }^{2}$.

We now consider an (exogenous) increase in risk, that is an increase in $l$ compensated for by an increase in $W_{o}$ such that the expected wealth $\left[\mu=W_{o}-p l-c(x)\right]$ remains constant ${ }^{3}$. More precisely, by differentiation of $\mu$ we obtain:

$$
\frac{d W_{o}}{d l}=p>0
$$

This compensated variation of $W_{o}$ and $l$ satisfies the properties of a mean preserving spread: constant mean and more weight in the tails for the riskier distribution.

The sign of the effect of the increase in risk on $x^{*}$ is given by:

$$
\frac{d x^{*}}{d l}=\frac{p L_{W_{0}}+L_{l}}{-L_{x}}
$$

\footnotetext{
${ }^{2}$ As already pointed out by Ehrlich and Becker [1972] and Hiebert [1983], risk-aversion is not sufficient to obtain the second-order condition.

${ }^{3}$ There are many ways to define a mean preserving increase in risk but they all lead to the same conclusion as the one selected here.
} 
where $L\left(x, W_{o}, l\right)$ stands for the first-order condition [see (2)] while $L_{x}, L_{w_{0}}$ and $L_{l}$ are its partial derivatives. As $L_{x}$ is negative by the second-order condition,

$$
\operatorname{sign}\left(\frac{d x^{*}}{d l}\right)=\operatorname{sign}\left(p L_{w_{0}}+L_{l}\right)
$$

As

$$
\begin{aligned}
& L_{w_{0}}=p_{x}\left[U^{\prime}(A)-U^{\prime}(B)\right]-c_{x}\left[(1-p(x)) U^{\prime \prime}(B)+p(x) U^{\prime \prime}(A)\right] \\
& L_{l}=-p_{x} U^{\prime}(A)+c_{x} p U^{\prime \prime}(A)
\end{aligned}
$$

it turns out after further transformations that:

$$
\operatorname{sign}\left(\frac{d x^{*}}{d l}\right)=\operatorname{sign}\left\{p_{x}\left[(p-1) U^{\prime}(A)-p U^{\prime}(B)\right]+c_{x p} p(1-p)\left[U^{\prime \prime}(A)-U^{\prime \prime}(B)\right]\right\} .
$$

Under risk aversion, the right-hand side of (5) is sign ambiguous while it is positive under risk neutrality ${ }^{4}$. Intuition suggests however that under risk aversion, an increase in risk should also increase $x^{*}$ since one suspects that under these circumstances, self-protection activities should become more valuable. As the result in (5) does remain ambiguous under risk aversion, we now turn to a more detailed analysis of this expression.

\section{Analysis of the model}

Under risk aversion, a sufficient condition to obtain $\frac{d x^{*}}{d l}>0$ is that $U^{\prime \prime}(A) \geq U^{\prime \prime}(B)$ which occurs whenever $U^{\prime \prime}(W) \leq 0$. This condition, in turn, is a sufficient condition for absolute risk aversion to be increasing in wealth. As this assumption is hard to admit because of its implication in risk theory (see Arrow [1971] and Pratt [1964]), this result deserves a careful attention. As (5) indicates, the ambiguity in the sign of $\frac{d x^{*}}{d l}$ stems from the presence of a negative term, namely $c_{x} p(1-p) U$ " $(A)$ which counteracts the three other positive ones.

The presence of the negative term in (5) is due to the specific structure of the self-protection problem which can be better understood by comparison with the self-insurance one briefly presented in the Appendix.

\footnotetext{
${ }^{4}$ In most contexts an increase in risk under risk neutrality does not affect the level of the decision variable. However, in the present framework, the increase in risk (hence in $l$ ) raises the marginal benefit of self-protection while its marginal cost remains constant. As the impact on $x^{*}$ goes in the right direction, this peculiarity of the problem does not affect our discussion of risk aversion.
} 
Under self-insurance the compensated increase in risk has a non-ambiguous positive effect on the level of the risk reducing activities in accordance with intuition. While both activities have a similar ex ante effect on expected utility, their impact strongly diverges ex post if the state of loss occurs. In this state, both activities cost money but self-insurance has a positive impact on final wealth by reducing $l$ which is not the case for self-protection ${ }^{5}$. This difference is captured precisely by the term $c_{x} p(1-p) U^{\prime \prime}(A)$ which - as should be noticed is evaluated in the state of loss. However, when $U^{\prime \prime}(W) \leq 0$, the negative term in $d x^{*}$ is more than (or exactly) outweighted by the one involving $U$ "' $(B)$, so that the total effect is unambiguous. On the other hand, when $U^{\prime \prime}>0$, the term involving $U$ " $(A)$ dominates $U$ "' $(B)$ and a negative response of $x^{*}$ to the increase in risk may obtain as indicated by the following example.

To show that under $U^{\prime \prime}>0 \frac{d x^{*}}{d l}$ may become negative, we consider the logarithmic utility function combined with the following data ${ }^{6}$ :

$$
W_{o}=6000, p(x)=.8-.005 x, l=5000 \text { and } c(x)=.1 x^{2} .
$$

Then $x^{*}=62.286$ so that the right-hand side of (5) evaluated at $x^{*}$ is negative, yielding the counterintuitive result $\frac{d x^{*}}{d l}<0$. As the logarithmic utility function exhibits decreasing absolute risk-aversion, we thus see that this assumption may be compatible with a negative $\frac{d x^{*}}{d l}$.

\section{Conclusion}

According to a well-known result in the literature, increases in risk for bets should induce risk-averse individuals to reduce their exposure to risk. Although this result holds true for market and self-insurance, we have shown here that it does not hold for self-protection activities even if one restricts oneself to the widely accepted class of utility functions with decreasing absolute risk aversion. However, under non decreasing absolute risk aversion, the intuitive result is again obtained for self-protection activities.

\section{APPENDIX}

To show that under self-insurance, the impact of increased risk on this activity is positive, we use $l=l(y, \beta)$ where $\mathrm{y}$ is the level of self-insurance activity while $\beta$ is a shift-parameter. By assumption $l_{y}<0, l_{\beta}>0$ and $l_{y \beta}=0$.

In this framework,

$$
E[U]=p U\left(W_{o}-c(y)-l(y, \beta)\right)+(1-p) U\left(W_{o}-c(y)\right)
$$

yielding the first-order condition

\footnotetext{
${ }^{5}$ We thank Harris Schlesinger who suggested, in a private correspondence, a similar explanation for our results concerning increases in risk aversion [1985]. See Briys and Schlesinger [1986] for more details.
}

${ }^{6} \mathrm{We}$ have checked that the second-order condition for a maximum is satisfied with this set of data. 


$$
L\left(y, W_{o}, \beta\right)=p\left(-U^{\prime}(A)\left(c_{y}+l_{y}\right)\right)-(1-p) U^{\prime}(B) \cdot c_{y}=0
$$

where $c_{y}+l_{y}$ is negative at the optimum.

A mean-preserving increase in risk is obtained when:

$$
\frac{d W_{o}}{d \beta}=p \cdot l_{\beta}>0
$$

and after easy manipulations:

$$
\operatorname{sign}\left(\frac{d y^{*}}{d \beta}\right)=\operatorname{sign}\left(U^{\prime \prime}(A) \cdot\left(c_{y}+l_{y}\right)-U^{\prime \prime}(B) c_{y}\right)
$$

which is clearly positive under risk-aversion.

It can easily be shown that a similar result holds for market insurance when there are only two states of the world and whether the insurance premium is actuarial or not.

\section{REFERENCES}

ARROW, K.J. [1971]: Essays in the Theory of Risk Bearing, New York: American Elsevier.

BRIYS, E. and H. SCHLESINGER [1986]: "Risk aversion and the propensities for self-insurance and self protection", H.E.C. Working Paper, Jouy-en-Josas.

BOYER, M. and G. DIONNE [1984]: "Sécurité routière, efficacité, subvention et réglementation", Actualité Économique, 60 (June 1984), 200-222.

DIONNE, G. and L. EECKHOUDT [1985]: "Self-insurance, self-protection and increased risk aversion", Economics Letters, 17 (February 1985), 39-42.

EHRLICH, I. and G. S. BECKER [1972]: "Market insurance, self-insurance and selfprotection", Journal of Political Economy, 80 (July-August 1972), 623-648.

HIEBERT, L. D. [1983]: "Self-insurance, self-protection and the theory of the competitive firm”, Southern Economic Journal, 49 (July 1983), 160-168.

KARNI, E. [1983]: "Increasing risk with state-dependent preferences: Economic consequences", Working Paper \#122, Department of Political Economy, John Hopkins University, 15 pages.

MEYER, J. and M. B. ORMISTON [1985]: "Strong increases in risk and their comparative statics", International Economic Review, 26 (June 1985), 425-438.

PRATT, J. W. [1964]: "Risk aversion in the small and in the large", Econometrica, 32 (January - April 1964), 122-136.

ROTHSCHILD, M. and J. E. STIGLITZ [1970]: "Increasing risk: I, A definition", Journal of Economic Theory, 2, 225-243.

ROTHSCHILD, M. and J. E. STIGLITZ [1971]: "Increasing risk: II, Its economic consequences", Journal of Economic Theory, 3, 66-84. 